\title{
Modeling, simulation and control of a doubly-fed induction generator for wind energy conversion systems
}

\author{
Boumerid Bensahila Med El Amine', Allali Ahmed ${ }^{2}$, Merabet Boulouiha Houari ${ }^{3}$, Denai Mouloud ${ }^{4}$ \\ ${ }^{1,2,3}$ Faculty of Electrical Engineering, University of Sciences and Technology of Oran Med Boudiaf, Algeria \\ ${ }^{3}$ Ecole Nationale Polytechnique of Oran, Algeria \\ ${ }^{4}$ University of Hertfordshire, United Kingdom
}

\begin{tabular}{l} 
Article Info \\
\hline Article history: \\
Received Mar 16, 2019 \\
Revised Jul 8, 2019 \\
Accepted Apr 9, 2020 \\
\hline
\end{tabular}

\section{Keywords:}

DFIG

MPPT

PWM

SimPowerSystems

Simulink

Wind energy

\begin{abstract}
In recent years, wind energy has become one of the most promising renewable energy sources. Various wind turbine concepts with different generator topologies have been developed to convert this abundant energy into electric power. The doubly-fed induction generator (DFIG) is currently the most common type of generator used in wind farms. Usually the DFIG generator is a wound rotor induction machine, where the stator circuit is directly connected to grid while the rotor's winding is connected to the grid via a three-phase converter. This paper describes an approach for the independent control of the active and reactive powers of the variable-speed DFIG. The simulation model including a 1.5 MW-DFIG driven by a wind turbine, a PWM back-to-back inverter and the proposed control strategy are developed and implemented using MATLAB/Simulink/SimPowerSystems environment.
\end{abstract}

This is an open access article under the CC BY-SA license.

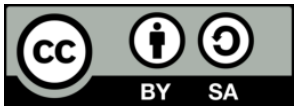

\section{Corresponding Author:}

Allali Ahmed,

Département de Génie Electrique, Faculté de l'électrotechnique,

Faculty of Electrical Engineering, University of Sciences and Technology of Oran Med Boudiaf, Algeria.

Email: allalia@yahoo.com

\section{INTRODUCTION}

In the last decade, interest in wind energy use has grown considerably. In Europe 30-40\% of newly installed renewable energy capacity was from wind power [1]. The U.S and China are currently the world leaders and dominate the global installed wind energy $[2,3]$. In 2010, the world's generation capacity from wind energy was $196.630 \mathrm{GW}$ and reached $240 \mathrm{GW}$ by the end of 2011 [4].

With the expansion of this renewable energy resource and its increased penetration into the electrical grids, wind turbine (WT) technology is currently one of the world's fastest growing, cost-effective renewable energy technologies in the market [5].

Wind power generation is subject to fluctuations due to the intermittent nature of wind energy and wind speed variations. This is more evident when multiple generators are connected to a weak grid [6].

Many topologies for wind turbines have been designed to reduce the fluctuations of the output power. Doubly-fed induction generators (DFIG) are the most widely used types of generators in wind energy conversion systems. This topology can offset its output power to stabilize fluctuations by a factor of typically up to $\pm 30 \%$. However, this device is still small considering the range of variation in practice of the wind speed. Researchers have proposed that energy storage systems are a desirable choice to further mitigate the effects of short-term wind fluctuations $[5,6]$.

Fixed-speed induction generators are constrained to operate near the synchronous speed, because the frequency is imposed by the network; the rotor speed is almost constant. Variable-speed wind turbine 
systems, on the other hand, are able to operate over a wide range of wind speeds. Furthermore, using an appropriate maximum power point tracking (MPPT) strategy, variable-speed wind turbines can produce maximum power at varying wind speed conditions. For variable-speed wind turbine systems with limited speed range, e.g. $\pm 30 \%$ of synchronous speed, the DFIG can be the solution of choice [7].

Unlike conventional wind turbine-driven synchronous generators, the output characteristic of the variable-speed wind energy conversion systems (WECS) depends not only on the dynamics of the generator but also on the converter control strategy employed. Control strategies of DFIG have been extensively discussed by several authors [8,9]. In [10], various control mechanisms for the DFIG have been reported using stator flux orientation in the reference frame $\alpha-\beta$. In [11] and [12], the stator flux oriented control of the generator DFIG has been studied but without any control of the grid side and DC link voltages. In [13], the authors studied the effect of active and reactive powers variations by a decoupling control method for the active and reactive powers. However, the influence of different load types on the grid and power quality according to the loads connected to the generator DFIG has not been addressed. This paper presents a comprehensive simulation study of the variations of reactive power on the grid under different load conditions (resistive, inductive and capacitive) and analyses the influence of these loads on the DFIG power factor which reflects the quality of the power generated.

The main advantage of using DFIGs in wind turbines is that they connect directly to the network via the three-phase stator windings and do not require additional converters. This configuration has become now very popular for variable-speed wind turbines [14]. This is mainly because the power electronic converter must handle only a fraction of $20 \%$ to $30 \%$ of the total power generated by the DFIG [14, 15]. Therefore, the losses in the power electronic converter can be reduced. Today, the DFIG is the most commonly used variable-speed machine in production units above $1 \mathrm{MW}$.

This paper presents a study of a DFIG dual-powered generator connected with industrial loads to learn the impact on the quality of voltage and current by applying inductive or capacitive loads.

The aim of this paper is to design an indirect vector control decoupling strategy to achieve independent control of the active and reactive powers of the DFIG-WT conversion system. A detailed model of the DFIG is used to design and evaluate the proposed control strategies. The authors present a technique of the stator quadrature flux along the axis to control the active and reactive powers of the DFIG. The proposed control approach is evaluated under resistive, inductive and capacitive loads connected between the DFIG and the grid.

The rest of the paper is organized as follows: Section 2 introduces the overall simulation model structure including mathematical models of the wind turbine. The proposed MPPT method used in the model is also presented. Section 3 of the paper presents the model of the DFIG and its indirect vector control scheme using Park transformation, the control of the DC side voltage. Finally, the simulation results and conclusions are summarized in Section 4 and 5 respectively.

\section{PROPOSED WIND ENERGY CONVERSION SYSTEM MODEL}

The proposed circuit is shown in Figure1. It consists of a three-blade wind turbine connected to a variable-speed DFIG. The stator circuit of the DFIG is directly connected to the grid, whereas the rotor winding is connected to the grid via two PWM-controlled IGBT-converters. The two converters are coupled through a DC link capacitor.

The rotor-side converter controls simultaneously the active and reactive powers by adjusting the amplitude, frequency and phase of the rotor voltages. The aim of the grid-side converter is to regulate the DC link voltage. The inputs to the control system are the voltages and currents on the source side and the voltage on the DC side. These quantities are transformed into their $\mathrm{d}$ and $\mathrm{q}$ components. A phase-locked loop circuit is used to synchronize the frequency of the system with the network frequency. 


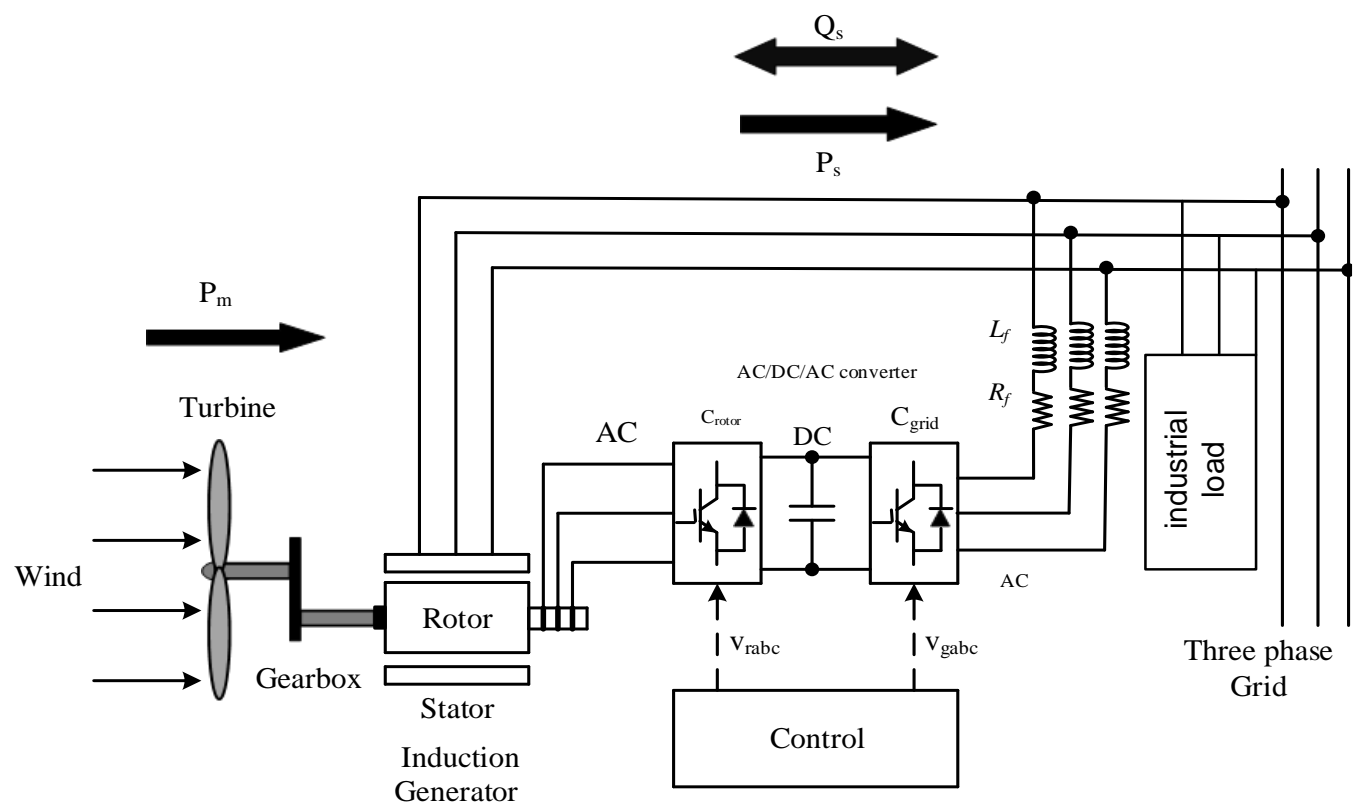

Figure1. Wind turbine with a DFIG

\subsection{Modeling the wind turbine with MPPT strategy}

The relationship between the wind speed and the aerodynamic mechanical power extracted from the wind can be described as follows $[16,17]$ :

$$
P_{m}=\frac{1}{2} \rho \cdot \pi \cdot R^{2} \cdot C_{p}(\lambda, \beta) \cdot v^{3}
$$

Pm: is the mechanical power of the wind turbine [W],

$\beta$ : is the orientation angle of the blades $\left[{ }^{\circ}\right]$.

The power coefficient $\mathrm{Cp}$ defines the aerodynamic efficiency of the wind turbine. It depends on the characteristic of the turbine and is a function of the speed ratio $\lambda$ and the orientation angle $\beta$ of the blade:

$$
C_{p}(\lambda, \beta)=C_{1}\left(\frac{C_{2}}{\lambda_{i}}-\left(C_{3}\right) \beta-C_{4}\right) e^{-\frac{C_{5}}{\lambda_{i}}}+C_{6} \lambda
$$

The values used for the coefficients C1 - C6 are given in Table 1 [18]:

\begin{tabular}{cccccc}
\multicolumn{6}{c}{ Table 1 Coefficients of the turbine } \\
\hline $\mathrm{C}_{1}$ & $\mathrm{C}_{2}$ & $\mathrm{C}_{3}$ & $\mathrm{C}_{4}$ & $\mathrm{C}_{5}$ & $\mathrm{C}_{6}$ \\
\hline 0.5176 & 116 & 0.4 & 5 & 21 & 0.0068 \\
\hline
\end{tabular}

With

$$
\frac{1}{\lambda_{i}}=\frac{1}{\lambda+0.08 \beta}-\frac{0.035}{\beta^{3}+1}
$$

$\lambda$ is defined as the ratio of the linear velocity at the end of the blade and is given by:

$$
\lambda=\frac{\Omega_{m} R}{v}
$$


It can be observed from Figure 2 that the power coefficient reaches a maximum for a pitch angle of $0^{\circ}$ and a particular value $\lambda$ nom $=8.1$ of the velocity ratio. The power coefficient value corresponding to $\lambda$ nom is Cpmax $=0.48$.

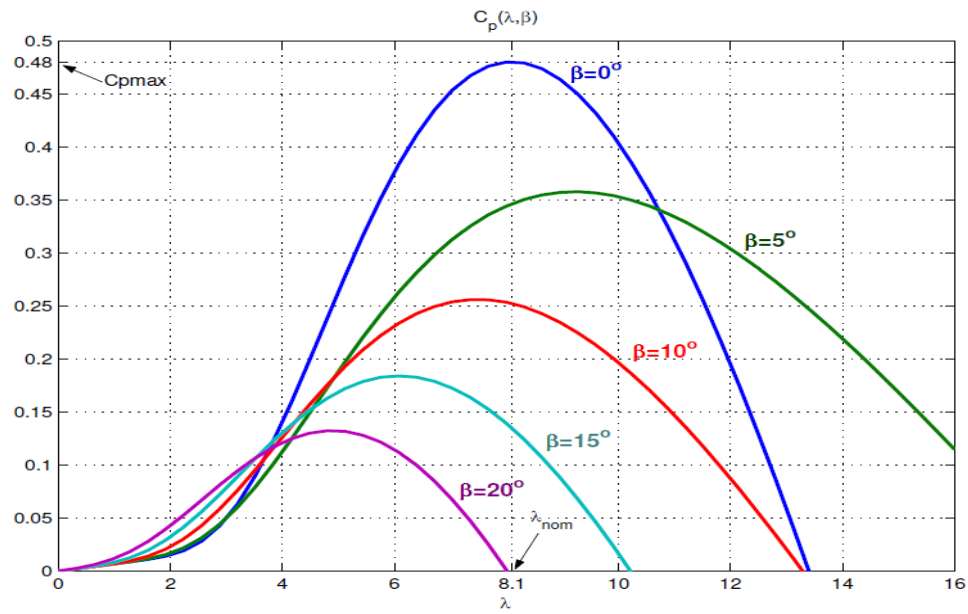

Figure 2. Characteristic of the power coefficient as a function of $\lambda$

Depending on the wind aerodynamic conditions, there exists an optimal operating point which allows the maximum power to be extracted from the turbine. This can be achieved by either controlling the rotational speed of the turbine or the power of the turbine. Several MPPT methods can be used either with or without the knowledge of the wind turbine characteristics [19]. In this study, the first method has been applied. The optimum rotation $\Omega \mathrm{m}$, opt for the mechanical transmission of the maximum wind turbine is given by [20]:

$$
\Omega_{m, o p t}=\frac{\lambda_{\text {nom }} v}{R}
$$

the following relation can be deduced:

$$
P_{m, \max }=K_{p, o p t} \Omega_{m, o p t}^{3}
$$

where:

$$
K_{p, o p t}=\frac{1}{2} \rho C_{p, \max } \frac{R^{5}}{\lambda_{\text {nom }}^{3}}
$$

thus, the corresponding optimum torque is:

$$
T_{m, o p t}=\frac{P_{m, \max }}{\Omega_{m, o p t}}=K_{p, o p t} \Omega_{m, o p t}^{2}
$$

On the power characteristic of a turbine (Figure 3), the locus of the point representing the maximum power is obtained by adapting the speed of the turbine (thick curve) to that of the wind speed. 


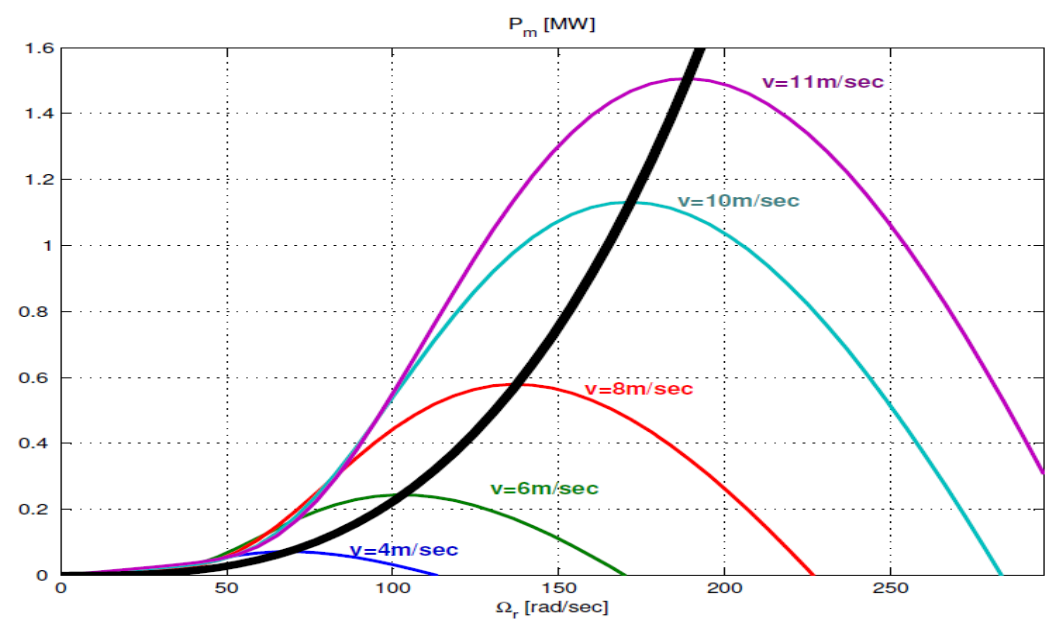

Figure 3. The characteristics of system optimum turbine

\subsection{Modeling of the DFIG}

The Park model of the DFIG is given by the following set of equations [21]:

$$
\left\{\begin{array}{l}
v_{d s}=R_{s} i_{d s}-\omega_{s} \phi_{q s}+\frac{d \phi_{d s}}{d t} \\
v_{q s}=R_{s} i_{q s}+\omega_{s} \phi_{d s}+\frac{d \phi_{q s}}{d t} \\
v_{d r}=R_{r} i_{d r}-\left(\omega_{s}-\omega_{r}\right) \phi_{q r}+\frac{d \phi_{d r}}{d t} \\
v_{q r}=R_{r} i_{q r}+\left(\omega_{s}-\omega_{r}\right) \phi_{d r}+\frac{d \phi_{q r}}{d t}
\end{array}\right.
$$

The stator flux equations are:

$$
\left\{\begin{array}{l}
\phi_{d s}=L_{s} i_{d s}+L_{m} i_{d r} \\
\phi_{q s}=L_{s} i_{q s}+L_{m} i_{q r}
\end{array}\right.
$$

Similarly, the rotor flux equations are:

$$
\left\{\begin{array}{l}
\phi_{d r}=L_{r} i_{d r}+L_{m} i_{d s} \\
\phi_{q r}=L_{r} i_{q r}+L_{m} i_{q s}
\end{array}\right.
$$

In these equations, Rs, Rr, Ls and Lr denote respectively the resistances and inductances of the stator windings and rotor, $\mathrm{Lm}$ is the cyclic mutual inductance, $\omega \mathrm{r}=\mathrm{P} . \Omega \mathrm{r}$ is the rotor speed (with $\mathrm{P}$ the number of pole pairs) and $\omega \mathrm{s}$ is the synchronous angular speed. vds, vqs, vdr, vqr, ids, iqs, idr, iqr, $\varnothing \mathrm{ds}, \varnothing q s$, $\varnothing \mathrm{dr}$ and $\varnothing q \mathrm{r}$ are respectively the direct and quadratic components of voltages, currents and fluxes in the stator and rotor. The active and reactive powers of the stator and rotor are obtained as:

$$
\left\{\begin{array}{l}
P_{s}=\frac{3}{2}\left(v_{d s} \cdot i_{d s}+v_{q s} \cdot i_{q s}\right) \\
Q_{s}=\frac{3}{2}\left(v_{q s} \cdot i_{d s}-v_{d s} \cdot i_{q s}\right)
\end{array}\right.
$$




$$
\left\{\begin{array}{l}
P_{r}=\frac{3}{2}\left(v_{d r} \cdot i_{d r}+v_{q r} \cdot i_{q r}\right) \\
Q_{r}=\frac{3}{2}\left(v_{q r} \cdot i_{d r}-v_{d r} \cdot i_{q r}\right)
\end{array}\right.
$$

The mechanical and electromagnetic torque are given by the following equations:

$$
\begin{aligned}
& T_{m}=T_{e m}+J \frac{d \omega_{r}}{d t}+f \omega_{r} \\
& T_{e m}=-P \frac{L_{m}}{L_{s}}\left(\phi_{q s} \cdot i_{d r}+\phi_{d s} i_{q r}\right)
\end{aligned}
$$

Where $\mathrm{J}$ is the moment of inertia and $\mathrm{f}$ is the viscous friction coefficient.

\section{CONTROL SCHEME OF THE GENERATOR AND CONVERTERS}

\subsection{Control of the Rotor Side Converter}

The stator flux vector is chosen to be aligned with the q-axis Park reference frame. The grid is assumed to be stable and therefore øsq is constant. The resistance Rs of the DFIG stator is neglected.

$$
\begin{aligned}
& \left\{\begin{array}{l}
\phi_{d s}=0 \\
\phi_{q s}=\phi_{s} \approx \frac{v_{d s}}{\omega_{s}}
\end{array}\right. \\
& \left\{\begin{array}{l}
v_{d s}=V_{s} \\
v_{q s}=0
\end{array}\right.
\end{aligned}
$$

Where Vs represents the r.m.s. value of the grid voltage. The torque (16) becomes:

$$
T_{e m}=-\frac{3}{2} \frac{P}{2} \frac{L_{m}}{L_{s}} \phi_{q s} i_{d r}
$$

The stator flux equations (11) become:

$$
\left\{\begin{array}{l}
0=L_{s} i_{d s}+L_{m} i_{d r} \\
\phi_{q s}=L_{s} i_{q s}+L_{m} i_{q r}
\end{array}\right.
$$

From (20), the equations linking the stator and rotor currents are:

$$
\left\{\begin{array}{l}
i_{d s}=-\frac{L_{m}}{L_{s}} i_{d r} \\
i_{q s}=\frac{\phi_{q s}}{L_{s}}-\frac{L_{m}}{L_{s}} i_{q r}
\end{array}\right.
$$

The active and reactive powers of the DFIG given by (18) are re-written as: 


$$
\left\{\begin{array}{l}
P_{s}=\frac{3}{2} V_{s} i_{d s}=-\frac{3}{2} \frac{L_{m}}{L_{s}} V_{s} i_{d r} \\
Q_{s}=\frac{3}{2} V_{s} i_{q s}=\frac{3}{2}\left(\frac{V_{s} L_{m}}{L_{s}} i_{r q}-\frac{V_{s}^{2}}{\omega_{s} L_{s}}\right)
\end{array}\right.
$$

Then the rotor voltages can be written as:

$$
\begin{aligned}
& \left\{\begin{array}{l}
v_{d r}=v_{d r}^{\prime}-\omega_{s l i p}\left(\phi_{q s} \frac{L_{m}}{L_{s}}+L_{r} \sigma i_{q r}\right) \\
v_{q r}=v_{q r}^{\prime}+\omega_{s l i p} L_{r} \sigma i_{d r}
\end{array}\right. \\
& \left\{\begin{array}{l}
v_{d r}^{\prime}=R_{r} i_{d r}+L_{r} \sigma \frac{d i_{d r}}{d t} \\
v_{q r}^{\prime}=R_{r} i_{q r}+L_{r} \sigma \frac{d i_{q r}}{d t}
\end{array}\right.
\end{aligned}
$$

Where the slip angular velocity $\omega$ slip, and total leakage coefficient $\sigma$ are given by:

$$
\omega_{s l i p}=\omega_{s}-\omega_{r}, \quad \sigma=1-\frac{L_{m}^{2}}{L_{s} L_{r}}
$$

The rotor side controller consisting of the active and reactive power controllers is shown in Figure 4.

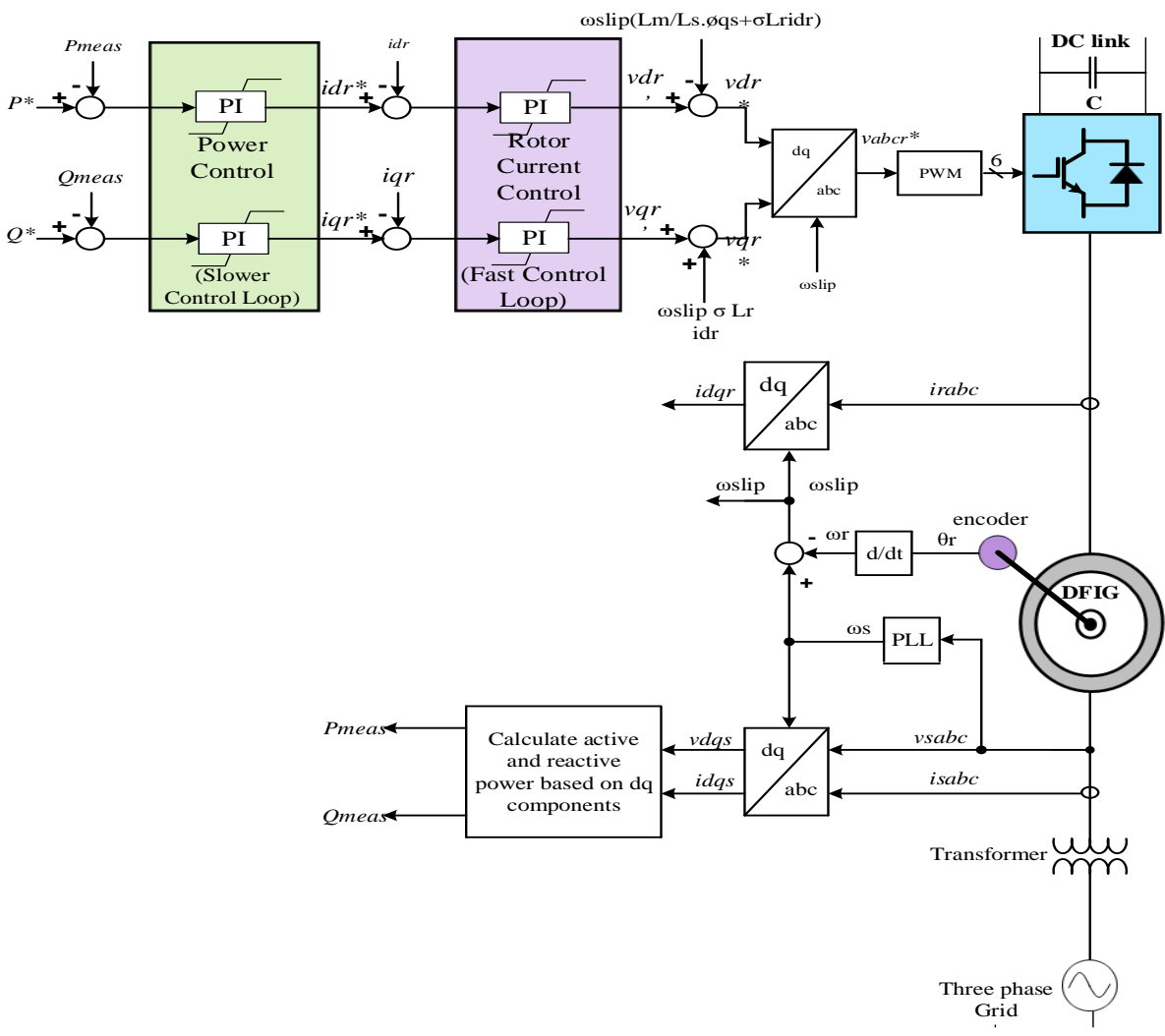

Figure 4. Rotor side controller for the DFIG

\subsection{Control of the grid side converter}


The grid side converter can also be used to control the power factor of the system by adding a control loop for the reactive power via the q-axis current. In the system, the quadratic component of the reference current is set to zero in order maintain a unity power factor. A similar control strategy was applied to the grid side converter, since the active and reactive powers of the grid side converter can be controlled independently by acting on the $d$ and $q$ components of the grid side voltage [5]. The grid side converter model in Park coordinates system is [22-25]:

$$
\frac{d}{d t}\left[\begin{array}{l}
i_{d} \\
i_{q}
\end{array}\right]=\left[\begin{array}{cc}
-\frac{R_{f}}{L_{f}} & \omega_{s} \\
-\omega_{s} & -\frac{R_{f}}{L_{f}}
\end{array}\right]\left[\begin{array}{l}
i_{d} \\
i_{q}
\end{array}\right]+\frac{1}{L_{f}}\left[\begin{array}{l}
v_{d}-v_{o d} \\
v_{q}-v_{o q}
\end{array}\right]
$$

Where: $\mathrm{Rf}$ and $\mathrm{Lf}$ are respectively the resistance and the leakage inductance of the grid-side transformer, vd and vq are the source voltage components and voq vod are the inverter voltages. Using the decoupling method by compensation, the inverter voltages can be written as:

$$
\left\{\begin{array}{l}
v_{o d}=e_{o d}-v_{o d 1} \\
v_{o q}=e_{o q}-v_{o q 1}
\end{array}\right.
$$

With the control coefficients:

$$
\left\{\begin{array}{l}
v_{o d 1}=L_{f} \frac{d i_{d}}{d t} \\
v_{o q 1}=L_{f} \frac{d i_{q}}{d t}
\end{array}\right.
$$

And the coefficients of compensation are obtained as:

$$
\left\{\begin{array}{l}
e_{o d}=-R_{f} i_{d}+L_{f} \omega_{s} i_{q}+v_{d} \\
e_{o q}=-L_{f} \omega_{s} i_{d}-R_{f} i_{q}+v_{q}
\end{array}\right.
$$

Neglecting the converter losses, the DC bus voltage vdc varies with the power exchanged between the turbine and the network and is given by:

$$
C \frac{d v_{d c}}{d t}=I_{d c}=I_{d c_{-} r o t o r}-I_{d c_{-} \text {grille }}
$$

The proposed control strategy for the DC link is depicted in Figure 5. It includes two control loops, an inner loop and an outer loop. The outer loop consists of a proportional and integral (PI) controller for regulating the DC link voltage. The output of the DC voltage controller represents the d-axis current reference idref from the source which is then compared with the measured current Idmeas. The quadrature component of the source current iq is used to control the flow of reactive power. As discussed earlier, the reactive power reference is set to zero in order to obtain a unity power factor. 


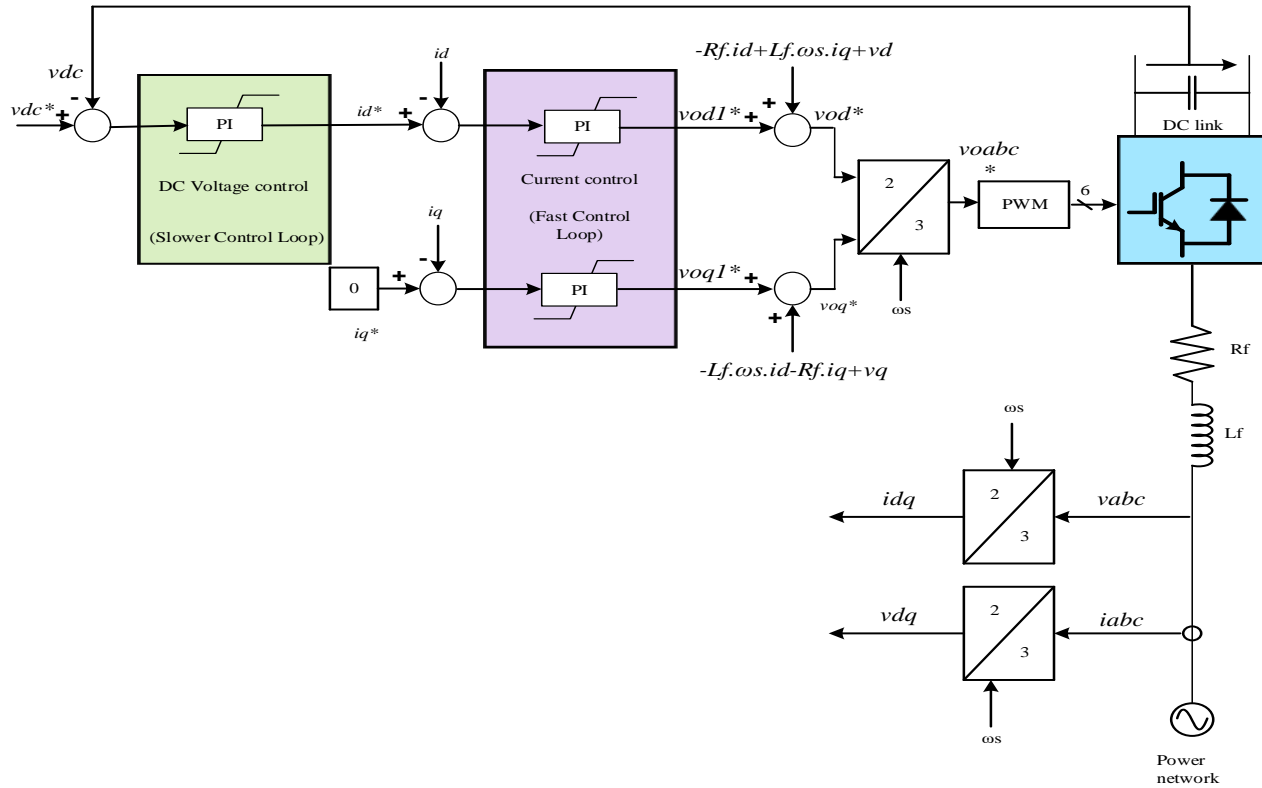

Figure 5. Controller side of the grid DFIG

\section{RESULTS AND DISCUSSION}

Figure 6 shows the overall model of the WECS and control scheme implementation in MATLAB/Simulink/SimPowerSystems. In the following, some simulation tests are presented to illustrate the performance of the proposed control system for the WECS.

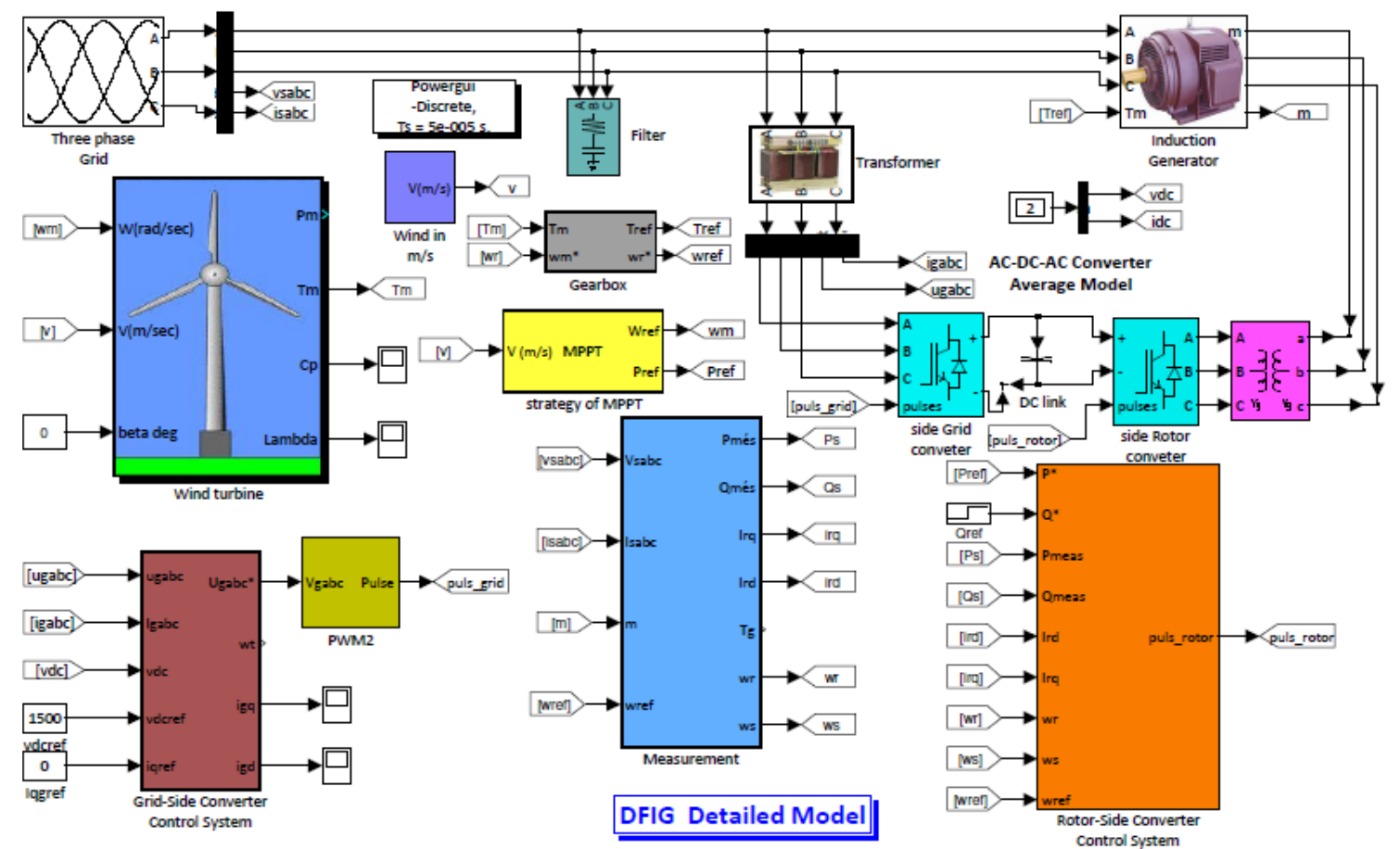

Figure 6. MATLAB/Simulink diagram of DFIG and control scheme 
The Side Grid Converter (SGC) adjusts the amplitude and frequency of the signal to be sent to the rotor of the DFIG: It acts on the voltages at the terminals of the rotor circuits. It varies the speed of the turbine and thus the power extracted.

Figure 7 shows the responses of direct (ird) and quadrature (irq) DFIG rotor currents and the stator active (Ps) and reactive (Qs) powers. The direct component ird controls the active power Ps. For a nominal power of Ps $=1.5 \mathrm{MW}$, the required forward current reaches a value of $1.5 \mathrm{kA}$. The reactive power Qs is controlled by the reactive component of current irq. The results show a good tracking performance when the reactive power reference is stepped from 0 to $0.5 \mathrm{MVAR}$ and then $-0.5 \mathrm{MVAR}$.

The reactive power supplied to the grid can be controlled by the reactive power generated or absorbed by the Rotor Side Converter (RSC) connected to the rotor. The reactive power is exchanged between this converter and the network, through the generator. Indeed, it absorbs reactive power to compensate for mutual inductances and leakage inductances. The converter connected to the network can also operate as a reactive power compensator.

It is noted that any variation in the rotor or rotor voltage frequency has a direct influence on the power and torque.

The quadrature component of the rotor current controls the active power, and the direct component controls the reactive power exchanged between the stator and the network as shown in Figure 7. It can be observed that both active and reactive powers of the DFIG follow their references.

The DC link voltage, the amplitude modulation index (MI) and the voltage vra and current ira in phase A of the rotor are shown in Figure 8. It can be noted that the DC voltage tracks perfectly its reference of $1.5 \mathrm{kV}$.

Figure 9 shows the responses of the electromagnetic torque, rotor angular speed, the speed ratio $\lambda$ and the power coefficient $\mathrm{Cp}$. The power factor $\mathrm{Cp}$ is expected to reach an optimal value of 0.48 after a short transient while the speed $\lambda$ reaches only the maximum of 8.1 .

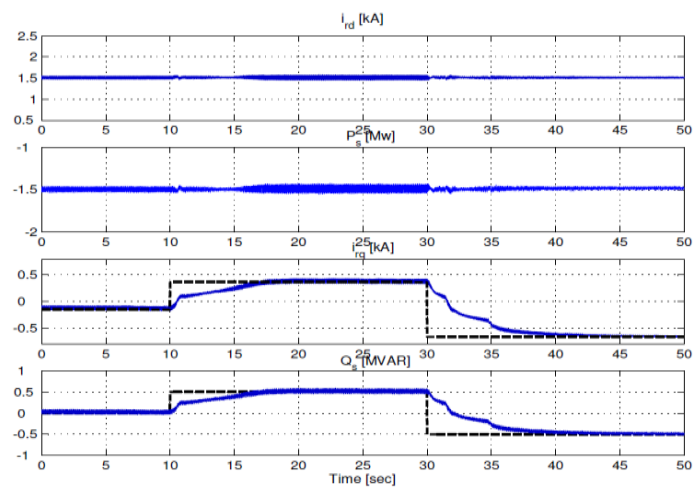

Figure 7. Active and reactive powers of stator and rotor currents

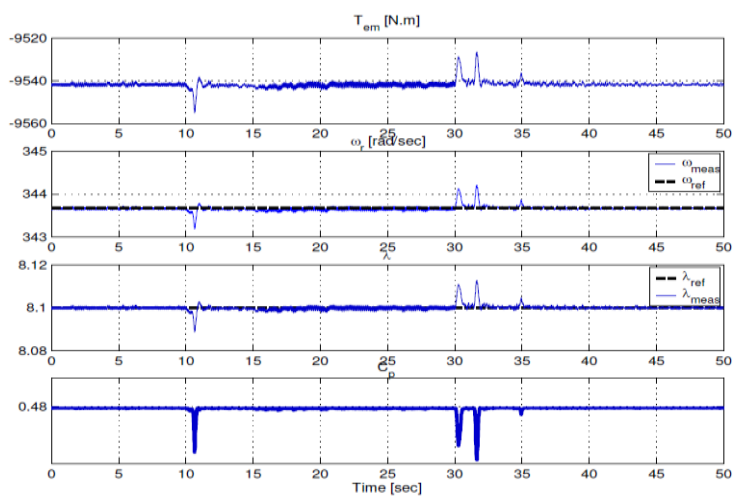

Figure 9. Response of the electromagnetic torque, rotor angular velocity, tip speed ratio $\lambda$ and power coefficient $\mathrm{C}_{\mathrm{p}}$

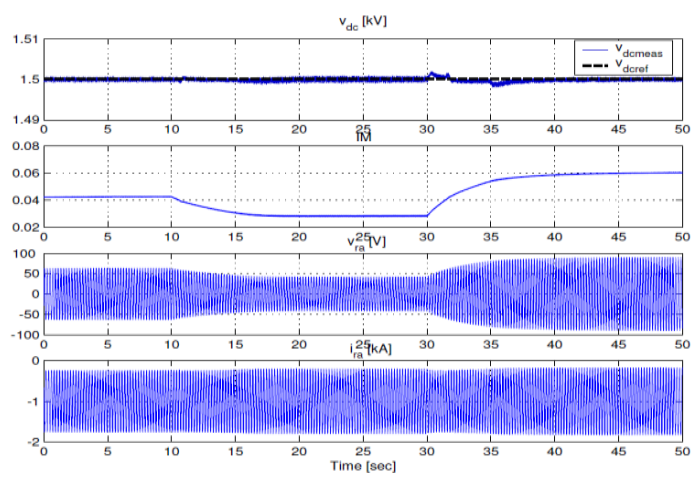

Figure 8. DC link, modulation index (MI), current and phase A voltage of the rotor

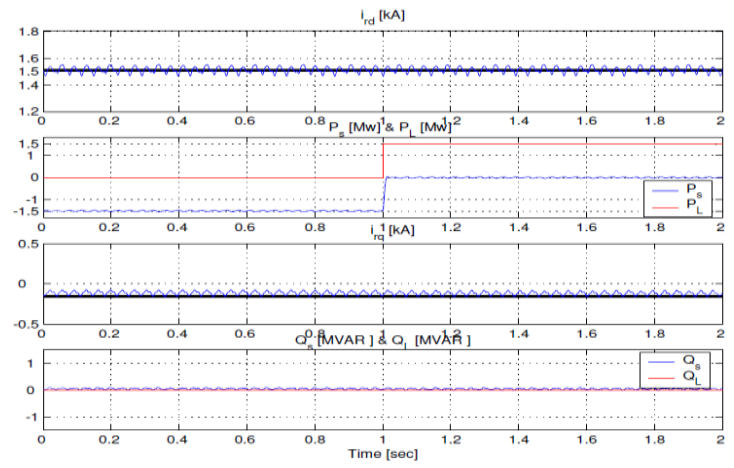

Figure 10. Active and reactive powers of the stator and rotor currents (resistive load conditions) 
The DFIG is now connected to resistive, inductive and capacitive loads respectively. The simulation results shown below are obtained at the same wind speed of $11 \mathrm{~m} / \mathrm{sec}$. Figure 10 shows the responses of the real (Ps) and reactive (Qs) powers of the stator, the real (PL) and reactive (QL) powers of the load and the resulting currents ird and irq in the case of a resistive load. Note that the grid absorbs the DFIG 1.5 MW active before the application of the load. After application of a load of $1.5 \mathrm{MW}$ at time $\mathrm{t}=1 \mathrm{sec}$, the power supplied by the DFIG is then consumed by the load and the power of the grid becomes zero. The results are illustrated in Figure 11. It can be noted that the voltage vdc follows its reference of $1.5 \mathrm{kV}$. The grid and load currents reached their steady-state values of $1.5 \mathrm{kA}$ and 0 A respectively before the application of the load. After the application of the load, the current of the load becomes $1.5 \mathrm{kA}$ and that of the grid becomes $0 \mathrm{~A}$.

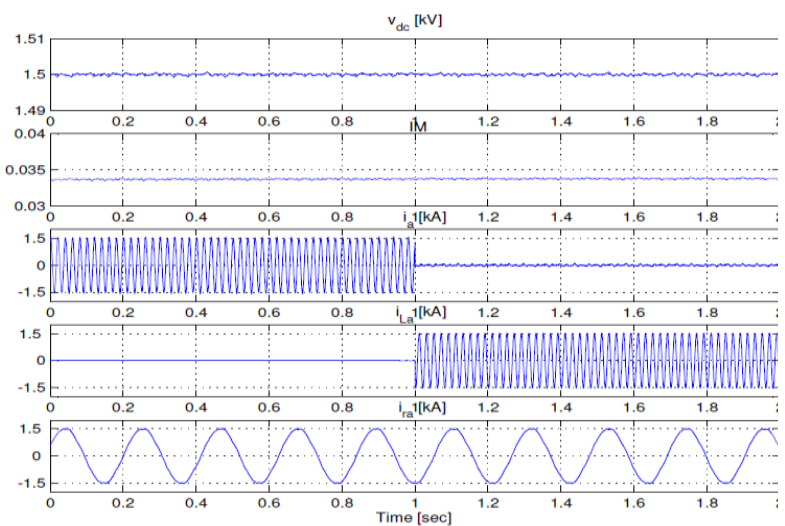

Figure 11. DC link voltage, amplitude modulation index (MI), phase A current of the grid and load and the current of DFIG rotor (resistive load conditions)

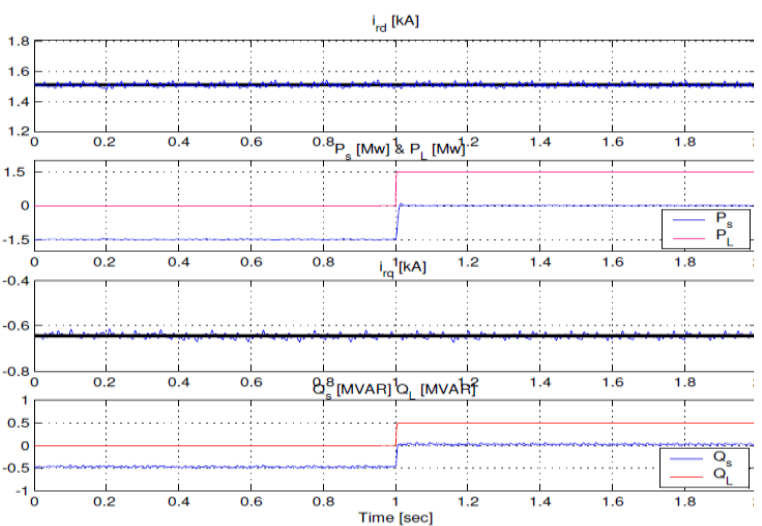

Figure 12. Active and reactive powers of stator, load and rotor currents (inductive load conditions)

Figure 12 shows the responses of real and reactive powers of stator (Ps and Qs) and those of the load (PL and QL) and the responses of the DFIG rotor currents ird and irq for an inductive load (PL $=1.5$ $\mathrm{MW}$ and $\mathrm{QL}=0.5 \mathrm{MVAR}$ ). Note that the grid absorbs the active power generated by the DFIG before applying the load. After application of the load at the instant $\mathrm{t}=1 \mathrm{sec}$, the necessary power to be consumed by the load is supplied by the DFIG and the power of the grid becomes zero. The load, the DC link voltage vdc, modulation index (IM), the currents of the grid and load and the DFIG rotor currents are illustrated in Figure 13. Similar remarks and conclusions can be drawn as in the case of resistive load.

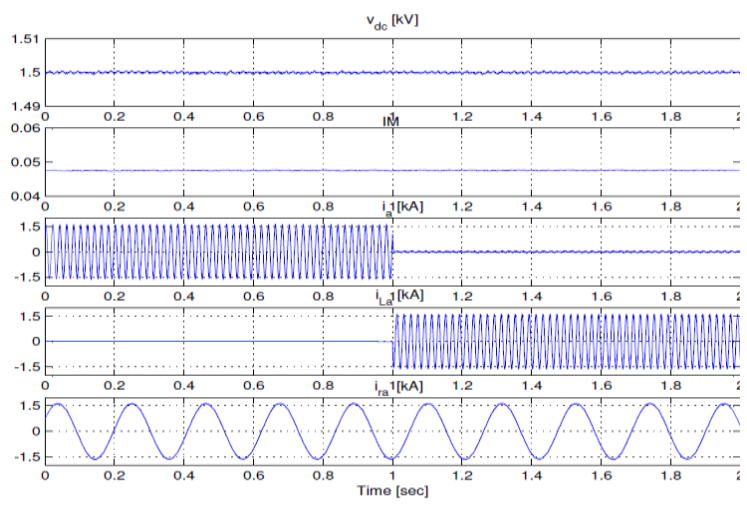

Figure 13. DC link voltage, amplitude modulation index (MI), phase A current of the grid and load and the current of DFIG rotor current (inductive load conditions)

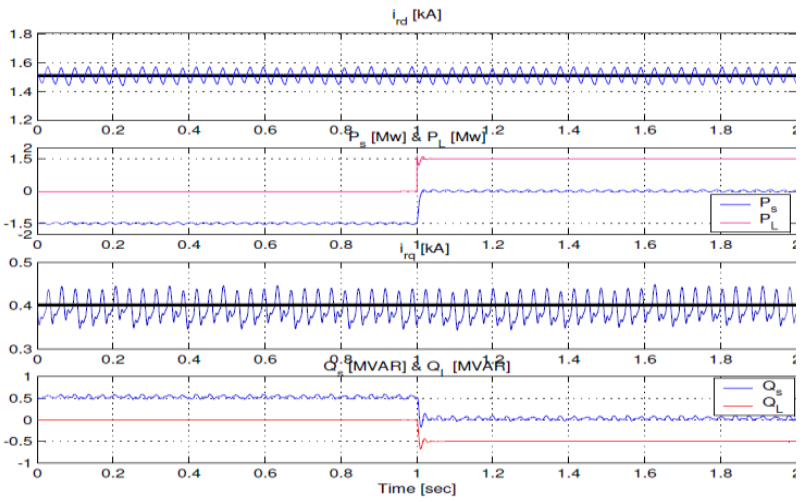

Figure 14. Active and reactive powers of stator and load and rotor currents (capacitive load conditions) 
A capacitive load is now introduced $(\mathrm{PL}=1.5 \mathrm{MW}$ and $\mathrm{QL}=0.5 \mathrm{MVAR})$ and Figure 14 show the results. Note that, in this case, the grid absorbs the active power generated by the DFIG before the load is applied. After application of the load at the instant $t=1 \mathrm{sec}$, the power supplied by the DFIG is consumed by the load and the power of the grid becomes zero. Figure 15 shows, the DC link voltage vdc, the modulation index (IM), the currents of the grid and the load and DFIG rotor currents. Table 2 summarizes the results obtained with the three types of loads and the effects on the power factor of the DFIG.

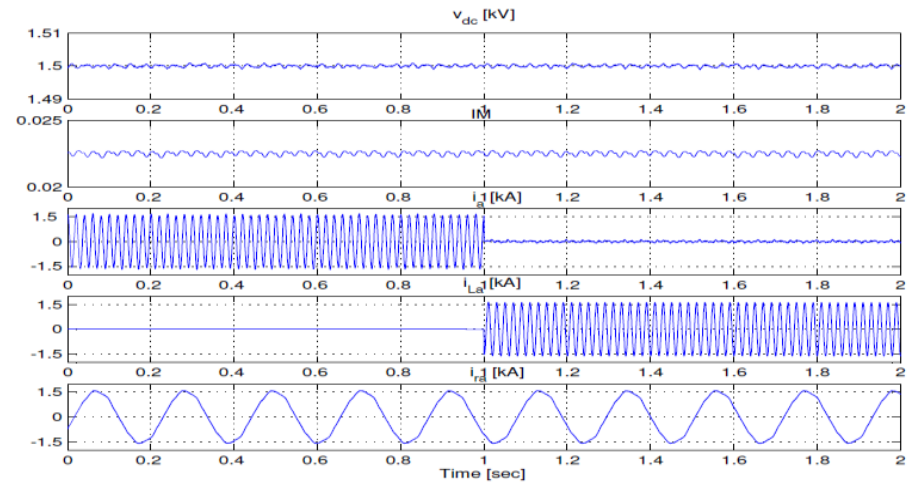

Figure 15. DC link voltage, amplitude modulation index (MI), phase A current of the grid and load and the current of DFIG rotor current (capacitive load conditions)

Table 2 Comparison of the three types of loads.

\begin{tabular}{llll}
\hline load & active power of DFIG [MW] & reactive power of DFIG [MVAR] & Power factor $\cos \varphi_{\text {DFIG }}$ \\
\hline resistive & 1.5 & 0 & 1 \\
inductive & 1.5 & -0.5 & 0.95 lagging \\
capacitive & 1.5 & 0.5 & 0.95 leading \\
\hline
\end{tabular}

Figure 16 shows the current waveforms of phase A for the three different types of load and the grid phase A voltage. This figure clearly illustrates that the voltage and the current generated by the DFIG are inphase when the load is resistive. The current is lagging and leading the voltage when the load is respectively inductive and capacitive.

One can say that the shapes of the curves show an acceptable tracking of the stator reactive power. The same applies to the stator active power and the total reactive power supplied to the network. This method of control presents remarkable performance in terms of reactive power control in the network through the wind system. This setting allows us to have a negative reactive power (capacitive behavior) or positive (inductive behavior) and even zero (unity power factor).

It can be noted that the reactive power that can be generated or absorbed is limited by the level of the rotor currents, these currents are also imposed by the switches of the IGBT power devices.

Figure 17 shows the waveforms of the instantaneous active power generated by the DFIG under these three load conditions.

In the case of capacitive load, ripples can be observed in Figure 17 due to the stator voltages of the DFIG. On the hand, in the case of inductive load, voltage drops appear in the network voltages which caused a reduction of these ripples in the stator power waveform. In addition, the inductance can filter the line currents which leads to a significant improvement of the power quality. 


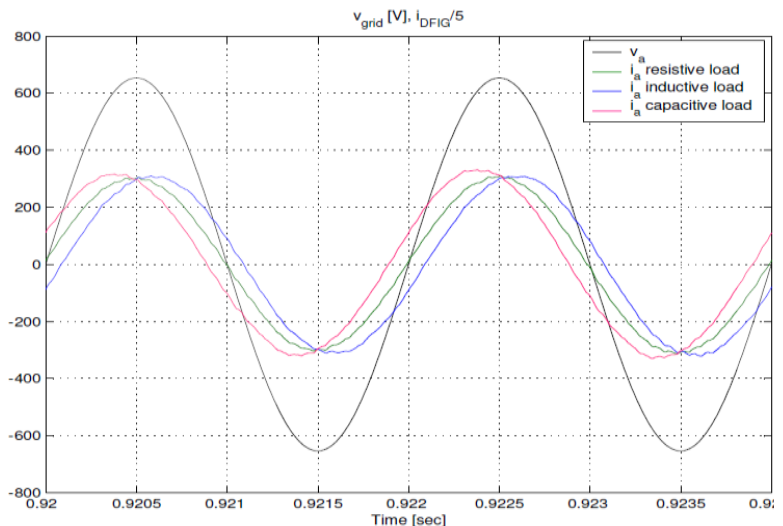

Figure 16. Phase A grid voltage and current waveforms for resistive, inductive and capacitive loads

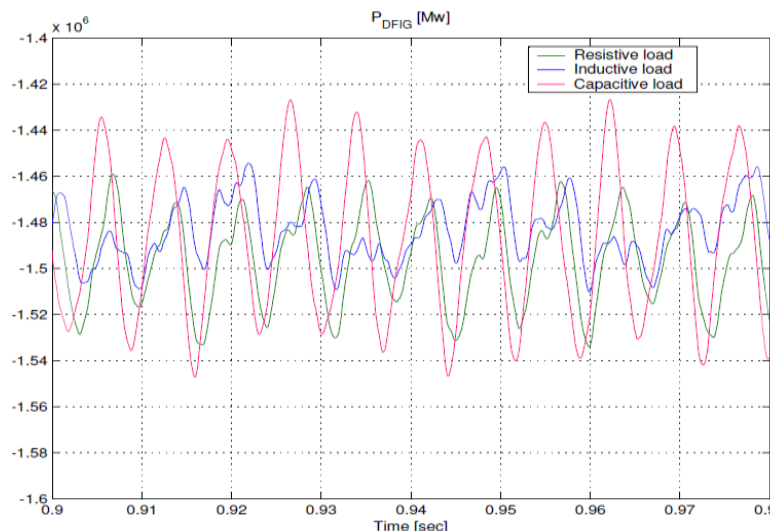

Figure 17. DFIG stator active powers for resistive, inductive and capacitive loads

\section{CONCLUSION}

This paper presented the modeling, simulation and control of a DFIG based wind conversion system connected to the grid. The overall system was implemented using MATLAB/Simulink and SimPowerSystems toolbox. The indirect vector control method is used to control the stator flux and hence the active and reactive powers of the DFIG. The reference of the active power generated by the DFIG is set according to the wind speed using a maximum power point tracking (MPPT) strategy. The reactive power set-point is varied according to the type load connected to the generator. Three types of load scenarios have been considered (resistive load inductive and capacitive) to demonstrate the influence of the load on the DFIG. The simulation results show the effectiveness of the decoupling controller and MPPT strategy under these three load conditions. The grid-connected DFIG simulation model presented in this work can be easily extended to include other compensating devices such as SVC (Static Var Compensator) or ASVC (Advanced Static Var Compensator) and can also be used to investigate other more robust control strategies to further improve the performance of the system in response to grid disturbances.

\section{REFERENCES}

[1] European Wind Energy Association. Wind Energy-The Facts: A Guide to The Technology, Economics and Future of Wind Power; Earthscan Publications: London, UK, March, 2009.

[2] Global Wind Energy Council. Global Wind 2008 Report. Available online: http://www.gwec.net/ fileadmin/documents/Global\%20Wind\%202008\%20Report.pdf (accessed on 10 December 2009).

[3] A. Pullen, L. Qiao, S. Sawyer (Eds.), Global Wind 2009 Report, Global Wind Energy Council, Brussels, 2010 http://www.gwec.net/index.php?id=167.

[4] "Worldwide energy report," Conf. World wind energy Renew. Energy Exhib, WWEA, Cairo, pp.6-8, 2010.

[5] S. Raúl, M. F. Luis, A. G. Carlos, J. Francisco, "Coordinate operation of power sources in a doubly-fed induction generator wind turbine/battery hybrid power system”, Journal of Power Sources, vol. 205, pp. 354-366, 2012.

[6] A. Petersson, T. Thiringer, L. Harnefors, T. Petru, "Modeling and Experimental Verification of Grid Interaction of a DFIG Wind Turbine," IEEE Trans. on Energy Conversion, vol. 20, No.4, pp. 878 886, 2005.

[7] G. Yuan, C. Jianyun, Y. Li, "Vector Control and Synchronization of Doubly Fed Induction Wind Generator System," 2004 IPEMC Proceedings, pp. 886-890, 2004.

[8] A. Dendouga, R. Abdessemed, M. L. Bendaas and A. Chaiba, "Decoupled Active and Reactive Power Control of a Doubly-Fed Induction Generator (DFIG)," Mediterranean Conference on Control and Automation, Athens-Greese IEEE, 2007.

[9] A. Abedi, M. Pishvaei, A. Madadi, H. M. Kelk, "Analyzing Vector Control of a Grid-Connected DFIG under Simultaneous Changes of Two Inputs of Control System," European Journal of Scientific Research, vol.45, no. 2, pp.221-231, 2010.

[10] J.P. Barton, D.G., "Infield, Energy storage and its use with intermittent renewable energy," IEEE Transactions on Energy Conversion, vol. 19, no. 2, pp. 441-448, 2004.

[11] C. Abbey, G. Joos, "Supercapacitor energy storage for wind energy applications", IEEE Transactions on Industry Applications, vol. 43, no. 3, 2007.

[12] W. Li, G. Joos, "A power electronic interface for a battery supercapacitor hybrid Energy Storage System for wind applications," in: 39th IEEE PESC, vol. 176, pp. 1762-1768, 2008.

[13] W. Leonhard, "Control of Electrical Drives," 2nd ed. Berlin, Germany: Springer-Verlag, 1996. 
[14] L. H. Hansen, L. Helle, F. Blaabjerg, and al, "Conceptual survey of generators and power electronics for wind turbines," Risø National Laboratory, Roskilde, Denmark, 2001.

[15] L. Xu and C. Wei, "Torque and reactive power control of a doubly fed induction machine by position sensorless scheme," IEEE Trans. Ind. Applicat., vol. 31, no. 3, pp. 636-642, 1995.

[16] C.K. Rai, "Non-Conventional Energy Sources of Energy", Khanna Publishers, 1996.

[17] L. Yazhou, M. Alan, L. Gordon and Y. Robert "Modeling of the Wind Turbine with a Doubly Fed Induction Generator for Grid Integration Studies", IEEE Transactions on Energy Conversion, vol. 21, no. 1, pp. 257-264, 2006.

[18] A. Kuperman, R. Rabinovici and G.Weiss, "A shunt connected inverter based variable speed wind turbine generation," Int. Jour. of electromotion, vol. 13, no. 1, pp. 67-72, 2006.

[19] R. Gagnon, B. Saulnier, G. Sybille, P. Giroux, "Modeling of a Generic High-Penetration No-Storage Wind-Diesel System Using Matlab/Power System Blockset," Global Wind power Conference, April, 2002.

[20] H. Siegfried, "Grid Integration of Wind Energy Conversion Systems," John Wiley \& Sons Ltd, 1998

[21] M.A. Abdullah, A.H.M. Yatim, C.W. Tan and R. Saidur, "A Review of Maximum Power Tracking Algorithms for Wind Energy Systems," Renewable and Sustainable Energt Reviews, vol. 6, no. 5, pp. 3220, 2012.

[22] F. Poitiers, T. Bouaouiche, M. Machmoum, "Advanced Control of Doubly-Fed Induction Generator for Wind Energy Conversion,” Electric Power Systems Research, vol.79, no. 7, pp. 1085, 2009.

[23] F. El Aamri, H. Maker, D. Sera and al, "A Direct Maximum Power Point Tracking Method for Single-Phase GridConnected PV Inverters," IEEE Transactions on Power Electronics, vol. 33, 2018.

[24] R. Pena, R. Cardenas, J. Clare, and P. Wheeler, "Control system for unbalanced operation of stand-alone doubly fed induction generators," IEEE Trans. Energy Convers, vol. 22, no. 2, pp. 544-545, 2007.

[25] L. Shuhui, A.H. Timothy, J. Jeff, "Integrated power characteristic study of DFIG and its frequency converter in wind power generation” Renewable Energy, vol. 35, no. 1, pp: 42-51, 2010. 